\title{
Adaptación de la enseñanza de la microbiología en el grado de podología incluyendo docencia práctica
}

\author{
María Luisa Gómez-Lus ${ }^{1}$, Pedro Bas ${ }^{2}$, Luis Alou ${ }^{3}$
}

Fecha de envío: 2 de diciembre de 2018 / Fecha de aceptación: 4 de mayo de 2019

Resumen. Con la adaptación al EEES (Espacio Europeo de Educación Superior), se ha comenzado a impartir Microbiología dentro de la materia de Biopatología, introduciendo como actividad docente los créditos prácticos de Microbiología para conseguir mejorar las competencias que deberán adquirir los estudiantes como parte de su formación integral. Se compararon los resultados de la evaluación de 34 alumnos del curso 2011-2012, analizando los resultados entre la pregunta de integración teórico-práctica (TP)y la que únicamente se había explicado en la clase teórica $(T)$.Se encontraron diferencias significativas $(\mathrm{p}<0,001)$ entre la nota media que presentaron los alumnos que habían superado la asignatura y los que no la habían superado para la prueba $\mathrm{T}$, mientras que estas medias no fueron estadísticamente significativas para la prueba TP .Podemos concluir que el aprendizaje evaluado en la pregunta TP ha sido satisfactorio en los dos grupos, incluso los alumnos que no han superado la asignatura han logrado alcanzar buenos resultados en esta prueba.

Palabras clave: Microbiología; prácticas; microbiota.

\section{[en] Adaptation of the teaching of microbiology in the degree of podology, including practical teaching}

\begin{abstract}
With the adaptation to the EHEA (European Higher Education Area ), Microbiology has begun to be taught within the field of Biopathology, introducing as a teaching activity the practical credits of Microbiology in order to improve the skills that students should acquire as part of their integral training. The results of the evaluation of 34 students of the 2011-2012 academic year were compared, analyzing the results between the question of theoreticalpractical integration (TP) and the one that had only been explained in the theoretical class (T). Significant differences were found $(p<0.001)$ between the average score of the students who had passed the course and those who had not passed it for the T test, while these means were not statistically significant for the TP test. We can conclude that the learning evaluated in the question TP has been satisfactory in both groups, even students who have not passed the course have achieved good results in this test.
\end{abstract}

Keywords: Microbiology; practices; microbiota.

Sumario: 1. Introducción. 2. Material y métodos. 3. Resultados. 4. Bibliografía.

Cómo citar: Gómez Lus, M. L.; Bas, P.; Alou, L. (2019) Adaptación de la enseñanza de la microbiología en el grado de podología incluyendo docencia práctica, en Revista internacional de ciencias podólogicas 13(1), 131-135.

Los autores declaran no tener ningún conflicto o interés económico

\footnotetext{
Área de Medicina, Departamento de Microbiología. Facultad de Medicina. Universidad Complutense de Madrid. Avda. Complutense s/n. 28040 Madrid, España.

mlgomezl@ucm.es

2 Área de Medicina, Departamento de Microbiología. Facultad de Medicina. Universidad Complutense de Madrid. Avda. Complutense s/n. 28040 Madrid, España.

pbas@ucm.es

3 Área de Medicina, Departamento de Microbiología. Facultad de Medicina. Universidad Complutense de Madrid. Avda. Complutense s/n. 28040 Madrid, España.

luisalou@ucm.es
} 


\section{Inrtroducción}

La Universidad Complutense de Madrid fue la Universidad española que aprobó los estudios de podología de acuerdo al Real Decreto 649/1988 para la obtención del Título de Diplomado en Podología impartiéndose la asignatura de Microbiología en el primer curso. Con la adaptación al Grado, se ha comenzado a impartir Microbiología dentro de la materia Biopatología en segundo curso, introduciendo cómo actividad docente los créditos prácticos de Microbiología para conseguir mejorar las competencias generales, transversales y específicas que deberán adquirir los estudiantes para mejorar el aprendizaje (1).

En este trabajo sehan planteadolos siguientes objetivos: En primer lugar,racionalizar la cuota de presencialidad en la puesta en marcha de los nuevos proyectos de grado ajustando la programación docente, incrementando el tiempo dedicado a las prácticas, seminario y otros procesos de aprendizaje, permitiendo que el alumno se implique manera activa y de manera cooperativa en la organización del estudio (2). En segundo lugar,mejorar el sistema de evaluación (3), midiendo la competencia y la habilidad para la resolución de problemas, cómo parte de su formación integral. $\mathrm{Y}$ en tercer lugar,medir el grado de satisfacción de los alumnos sobre la actividad práctica realizada.

\section{Material y métodos}

La actividad se realizo por los alumnos que cursaban Microbiología integrada en Biopatología ( $2^{\circ}$ de Grado de Podología), en tres días, durante dos horas cada día, entregando hojas de trabajo de cada uno de los apartados de la práctica.

El primer día, para estudiar la microbiota del pie sano, las muestras de pie se sembraron mediante hisopo en los siguientes medios de cultivo: medio agar sangre y medio Sabouraud, realizándose a las 24 horas la visión directa con tinción de Gram y la identificación bioquímica . Se desarrollo un estudio de la sensibilidad a los antimicrobianos, que se interpretó a las 48 horas y con esos datos redactaron un resultado microbiólogico estableciendo las bases del cronograma de diagnóstico microbiológico.

Posteriormente se valoró el impacto sobre el aprendizaje de la asignatura en los alumnos que superaron la asignatura y los que no la superaron. Para comparar la media de la nota obtenida por los alumnos que habían superado la asignatura y los que no se utilizó la prueba t-student.

Al finalizar actividad se valoraba la calidad de la enseñanza práctica recibida, del 1 al 5, resaltando aspectos para mejorar las competencias y habilidades alcanzadas con las actividades prácticas de Microbiología.

\section{Resultados}

Se compararon los resultados de la evaluación de 34 alumnos comparando los resultados entre la pregunta de integración teórico-práctica que se había desarrollado en la clase teórica y en la práctica (Pregunta 2) y una pregunta de teória que únicamente se había explicado en la clase teórica (Pregunta 5).

Al comparar la media de la pregunta 2 y la 5 entre los alumnos que habían superado la asignatura (Grupo 1- 76.47\%) y los que no la habían superado (Grupo 2- 23.52\%), se observó que en la pregunta 2 el grupo 1 tenía una media de 1.69 mientras que el grupo 2 tenía una media de 1.18. En relación a la pregunta 5 el grupo 1 tenía una media de 0.99 , mientras que el grupo 2 tenía una media de 0.15 .

$\mathrm{Se}$ encontraron diferencias significativas $(p<0,001)$ entre la nota media que presentaron los alumnos que habían superado la asignatura y los que no la habían superado para la prueba 5 , mientras que estas medias no fueron estadísticamente significativas para la prueba 2 (Figura 1). 


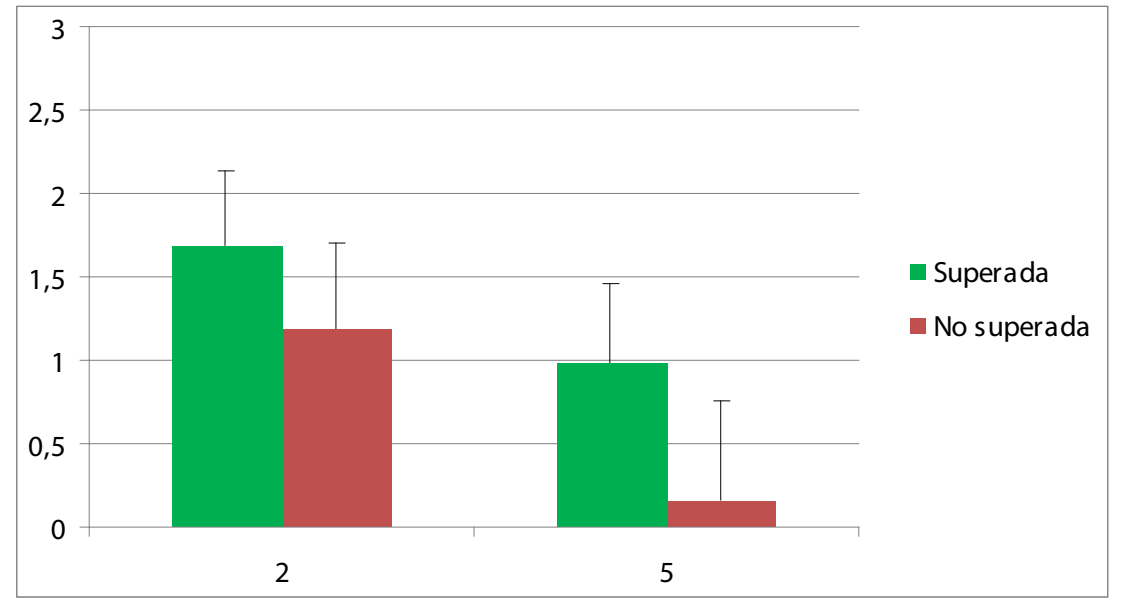

Figura 1.- Nivel de calificación relacionado con el aprendizaje teóricopráctico integrado (2) y teórico (5) en la superación de la asignatura

\begin{tabular}{|l|l|l|}
\hline & \multicolumn{1}{|c|}{$\begin{array}{c}\text { Diplomatura } \\
\mathbf{2 0 0 9 - 2 0 1 0} \\
\mathbf{N}^{\mathbf{2}} \text { alumnos (\%) }\end{array}$} & $\begin{array}{c}\text { Grado } \\
\mathbf{2 0 1 1 - 2 0 1 2} \\
\mathbf{N}^{\mathbf{0}} \text { alumnos (\%) }\end{array}$ \\
\hline MH & $2(4.44 \%)$ & $1(2.7 \%)$ \\
\hline Sobresaliente & $4(8.89 \%)$ & $4(11.11 \%)$ \\
\hline Sobresaliente & $6(13,33 \%)$ & $5(13,81 \%)$ \\
\hline Notable & $12(26.67 \%)$ & $8(22.2 \%)$ \\
\hline Aprobado & $11(24.44 \%)$ & $13(36.1 \%)$ \\
\hline Suspenso & $5(11.11 \%)$ & $8(22.22 \%)$ \\
\hline No presentado & $11(24.4 \%)$ & $2(5.5 \%)$ \\
\hline TOTAL & 45 & 36 \\
\hline
\end{tabular}

Tabla 1.- Calificaciones obtenidas en la diplomatura y el grado de licenciatura

Podemos concluir que el aprendizaje evaluado en la pregunta 2 ha sido satisfactorio en los dos grupos, incluso los alumnos que no han superado la asignatura han logrado alcanzar buenos resultados en esta prueba.

En relación a las calificaciones finales en el primer año de la impartición en el grado de Podología se aprecia un menor porcentaje de alumnos no presentados (Diplomatura 20091010: 24.4\% - Grado 2011-2012: 5.5\%) y se ha reducido el número de alumnos que no superaron la asignatura (Diplomatura 20091010: 35\% - Grado 2011-2012: 27.72\%), por lo que se reconsiderará incrementar las clases prácticas, ya que mejoran el aprendizaje destacando el impacto positivo en la mayoría de alumnos $(4,5)$, alcanzándose el objetivo de integrar los conocimientos teóricos y la formación práctica (Tabla 1 y Figura 2). 


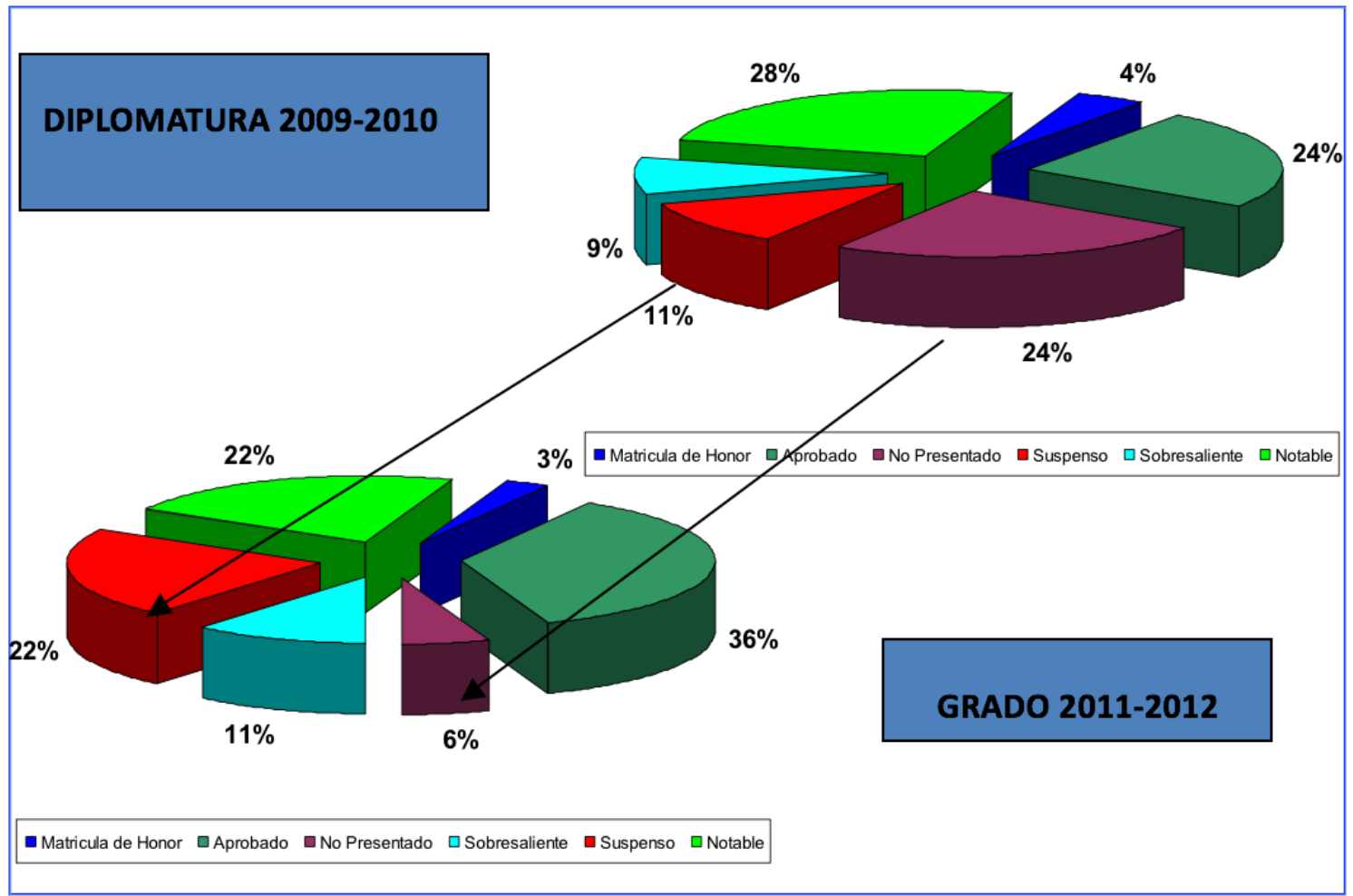

Figura 2.- Comparación de las calificaciones de la Diplomatura 2009-2010 y del Grado 2012-2012

Por último destaca la buena valoración por parte de los alumnos, destacando aspectos cómo la mejora del aprendizaje en relación con la lectura, la comprensión de los procedimientos diagnósticos de recogida de muestras y su cultivo y la diferenciación entre bacterias, pese a que algunos refieren que no les ha incrementado la motivación por la Microbiología. (Tabla 2) Consideramos que en líneas generales este tipo de estudios pueden optimizar la calidad de la docencia de la Microbiología en los estudios de Grado (6).

\begin{tabular}{|l|c|c|c|c|c|}
\cline { 2 - 5 } \multicolumn{1}{l|}{} & $\begin{array}{c}1 \\
\%\end{array}$ & $\begin{array}{c}2 \\
\%\end{array}$ & $\begin{array}{c}3 \\
\%\end{array}$ & $\begin{array}{c}4 \\
\%\end{array}$ & $\begin{array}{c}5 \\
\%\end{array}$ \\
\hline Ha mejorado mi aprendizaje sobre el tema & & & 8,57 & 57,1 & 34,2 \\
\hline La actividad es clara & & & 11,4 & 51,4 & 37,4 \\
\hline $\begin{array}{l}\text { He aprendido mas de esta manera que con la } \\
\text { lectura }\end{array}$ & & & 11,4 & 25,7 & 62,8 \\
\hline Ha aumentado mi interés por la Microbiología & & 5,7 & 14,2 & 34,2 & 42,8 \\
\hline $\begin{array}{l}\text { Con esta actividad he aprendido mas sobre la } \\
\text { microbiota de la piel y la diversidad bacteriana }\end{array}$ & & & 11,4 & 48,5 & 40 \\
\hline
\end{tabular}




\begin{tabular}{|l|c|c|c|c|c|}
\hline $\begin{array}{l}\text { Esta actividad permite aplicar a la práctica mi } \\
\text { conocimiento de lo aprendido en Bacteriología }\end{array}$ & 2,8 & & 14,2 & 42,8 & 40 \\
\hline $\begin{array}{l}\text { Esta actividad me ha permitido entender mejor } \\
\text { los procedimientos diagnósticos de recogida de } \\
\text { muestras y su cultivo }\end{array}$ & & & 8,57 & 31,4 & 60 \\
\hline $\begin{array}{l}\text { Con esta actividad puedo realizar una tinción de } \\
\text { una bacteria y diferenciarla para posteriormente } \\
\text { identificarla }\end{array}$ & & 2,8 & 17,1 & 34,2 & 36,1 \\
\hline $\begin{array}{l}\text { Mediante esta actividad puedo valorar si una } \\
\text { bacteria es Gram postiva y Gram negativa }\end{array}$ & & 2,8 & 34,2 & 34,2 & 28,5 \\
\hline $\begin{array}{l}\text { Esta actividad me ha permitido visualizar la } \\
\text { diversidad bacteriana de la microbiota de la piel } \\
\text { y su relación con la ausencia o presencia de } \\
\text { infección }\end{array}$ & & & 28,5 & 71,4 \\
\hline
\end{tabular}

Tabla 2.- Valoración de los estudiantes sobre los diferentes objetivos alcanzados con la actividad

\section{Bibliografía}

1. Gómez-Lus ML, Alou L, Ramos MC. Prieto J. Aplicación de nuevas metodologías en el aprendizaje de la Microbiología. XI Congreso Nacional de la SEQ. Madrid, 5-8 Octubre 2011.

2. Chaudhry MA. Assessment of Microbiology students' progress with an audience response system. Journal of Microbiology and Biology Education, 2011;vol.12,2: 200-201.

3. Johnson MT. Impact of on line learning modules on medical student Microbiology examination scores. Journal of Microbiology and Biology Education, 2008;vol.9: 25.29.

4. Lee VS and Hyman M. Helping educational reforms to succeed in a Microbiology Department. Microbe,2009; vol. 4, 5:219-223.

5. Peteroy-Kelly MA. A discussion group enhances the conceptual reasoning skills of students enrolled in a large lecture-format introductory biology course. Journal of Microbiology and Biology Education,2007; vol.8:13-21.

6. Gómez-Lus Centelles ML, Alou L, Prieto J. Integrando el aprendizaje activo de la Microbiología en el Grado de Medicina: evolución de la implicación de los estudiantes. Educación Médica. 2018; 19 (2): $77-81$. 